Pak. j. sci. ind. res. Ser. B: biol. sci. 2018 61B(2) 78-83

\title{
Development and Characterisation of Fig (Ficus carica) Leaves Tea with Special Reference to Hypoglycemic Effect
}

\author{
Maham Gillania*, Hira Iftikhar ${ }^{\mathrm{a}}$, Imran Pasha ${ }^{\mathrm{b}}$ and Asma Lodhi ${ }^{\mathrm{a}}$ \\ ${ }^{a}$ Institute of Home Sciences, University of Agriculture, Faisalabad, Pakistan \\ ${ }^{b}$ National Institute of Food Science and Technology, University of Agriculture, Faisalabad, Pakistan
}

(received December 2, 2016; revised July 26, 2017; accepted August 1, 2017)

\begin{abstract}
The leaves of Ficus carica (Fig) possess wide range of biological activities and are used to treat diabetes and its complications. The aim of the study was to evaluate the hyperglycemic and antioxidant effect of tea of Ficus carica leaves on normal and hyperglycemic rats. Effect of fig leaves tea was investigated on blood glucose level, daily food intake, daily water intake, body weight gain and its effect with insulin. Insulin was administered intravenously. Fig leaves tea was orally administered to four group of rats. Oral administration of fig leaves tea for 15 days exhibited a significant hypoglycemic effect in hyperglycemic rats at different times of a day. Highest hypoglycemic effect of tea was observed at $3 \mathrm{~h}$ which shows that leaves of Ficus carica possess significant short term hypoglycemic effect and not so significant long term hypoglycemic effect. When comparison was made between two insulin treatments (10U and $5 \mathrm{U}$ insulin) with $1 \mathrm{~mL}$ Ficus carica tea, no significant difference was observed with these two doses, which means that when given in combination of fig leaves tea even $50 \%$ decrease of dose of insulin did not produce significant difference in blood glucose level.
\end{abstract}

Keywords: diabetes mellitus, fig leaves, hyperglycemia, herbal medicine

\section{Introduction}

Diabetes mellitus is one of the most prominent health problems in all countries, and in spite of great improvements in its treatment, serious complications are still observed. Pakistan is the $7^{\text {th }}$ country in the list of diabetes prevalence. 6.9 million people are affected and this number will grow to 11.5 million by 2025 unless control measures are achieved, as estimated by the International Diabetes Federation (Hayat and Shaikh, 2010). Diabetes is a clinical syndrome characterised by chronic hyperglycemia and disturbances in carbohydrates, lipids and protein metabolism. The disease may result from defects in insulin secretion, insulin action or both (Imran et al., 2013).

Most effective treatments of diabetes mellitus include insulin and hypoglycemic agents, but these medications result in undesirable side effects. The recent interest in natural therapies and herbal medicine has motivated the investigation of plants that have been used in relation to diabetes. But the successful treatment involves the correct and logical use of herbal medicines or chemical drugs. Proper diet and alternative therapies can reduce the cost of treatment and prevent or cure many cases of type II diabetes and improve some cases of type I diabetes (Zohary and Hopf, 2000).

\footnotetext{
*Author for correspondence;

E-mail: Maham.gillani2075@gmail.com
}

Plants have been used by ancient people for the betterment of quality of life and is being used as medicine, food, shelter, clothing, hunting and spiritual ceremonies. Two most reliable reasons for popular plant management includes its use as food and as medicine. The health benefits and nutritional roles of these plants are being reported in many surveys worldwide (Barolo et al., 2014).

Ficus carica is commonly referred as "Fig". It is one of the five plants mentioned in Quran along with olive, dates, pomegranates and grapes. Ficus carica plant (fig tree) belongs to a Moraceae or (mulberry family) and is one of the unique Ficus species that is spread widely in tropical and subtropical countries (Patil and Patil, 2011).

Each part of fig plant has several medicinal uses. The fruit part of Ficus carica has a rich flavour with high sugar content and low acid complement. There are so many beneficial vitamins and minerals in Ficus carica like vitamin $A$, vitamin $C$, iron and calcium. Leaves of this plant are rich in rutin, quercetin, sapogenin, coumarins and psitaraxasteryl ester. Fig fruit is considered to have antidepressant, emollient and laxative effects, dried leaves are used to treat asthma and painful conjunctivitis (Merzouki et al., 2000; Kenneth, 2000; Murray et al., 1999). 
There are reports about the special effect of fig leaves (Ficus carica) on diabetes (Konyaloglu et al., 2005; Jouad et al., 2001). It was found that the leaves of fig plant have high total phenol and flavonoid content which can act as strong antioxidants (Leporatti and Ivancheva, 2003). Some researchers also suggested that there are more phenolic substances in the leaves of the plant in comparison with stem bark and fruit (Sirisha et al., 2010).

Aqueous and organic extract of leaves of Ficus carica had similar hypoglycemic effect in diabetic rats and it was also studied that diabetic complications may be caused as a result of oxidative stress (Perez et al., 2003).

Several studies have shown anti-diabetic effects of various parts of fig plants. Hypoglycemic action is significant in fig leaves (Kar et al., 2003; Perez et al., 2003; Grover et al., 2002) fruits (Wadood et al., 2003), stem and bark (Musayabayne et al., 2007; Kar et al. 2003) and root (Singh et al., 2009).

Meaningful hypoglycemic effect occurred in type I diabetes patients by oral fig-leaf decoction (Serraclara et al., 1998). Blood glucose level was decreased by oral consumption of aromatic water leaves of Ficus carica in normal and diabetic rats (Rashidi et al., 2011). In this study attempts were made to check the hypoglycemic effect of Ficus carica leaves in diabetic rats.

\section{Materials and Methods}

Procurement of raw material. Research was conducted in the Institute of Home Sciences, UAF and further analysis was carried out in post-graduate laboratory at National Institute of Food Science and Technology. Fresh leaves of Ficus carica were collected from nursery of Horticulture Department, University of Agriculture. Faisalabad.

Product development. In the product development phase, teabags were prepared with leaves of Ficus carica. Stems and branches were stripped off and the leaves were washed with the clean water, blanched and dried under the shed for one week. After drying, leaves were pulverised and sieved. The tea was prepared by the fig leaves.

Antioxidant potential. Water and methanol extract of fig leaves were analysed for phenol and flavonoid content.

Flavonoid content determination. Total flavonoid content of water and methanol extract of fig leaves were analysed in a spectrophotometer using the method explained by German Pharmacopoeia (Arzneibuch, 1996).

The flavonoids in AlCl3-complex obtained after acid hydrolysis were measured. This method is commonly used for the determination of flavonoid content and the amount of flavonoid is expressed as percent of extracts.

Phenol content determination. Total phenolic content of water and methanol extracts of fig leaves were estimated spectrophotometrically using Folin- Ciocalteau method (Singleton et al., 1999). The extract $(125 \mu \mathrm{L})$ was mixed with $125 \mu \mathrm{L}$ of Folin-Ciocalteau reagent along with $500 \mu \mathrm{L}$ of distilled water and allowed to stand for $5 \mathrm{~min}$ at $22^{\circ} \mathrm{C}$. Following resting period, 4.5 $\mathrm{mL}$ of sodium bicarbonate solution $(7 \%)$ was added to the mixture. After $90 \mathrm{~min}$, absorbance was measured at $765 \mathrm{~nm}$ using spectrophotometer against control. Total polyphenols were calculated and expressed as gallic acid equivalent (mg gallic acid/100g).

Sensory evaluation. Fig leaves tea was evaluated for general appearance, colour, taste, mixing ability, aroma and overall acceptability by trained taste panel using 9-point Hedonic score system following the guidelines of Meilgaard et al. (2007) with following individual scores: liked extremely-9, liked very much- 8 , liked moderately-7, liked slightly-6, neither liked nor disliked5 , disliked slightly-4, disliked moderately-3, disliked very much-2 and disliked extremely-1, to find out the most suitable composition of tea for commercialization.

Bio efficacy trial. To evaluate the therapeutic potential of fig leaves tea against hyperglycemia, an efficacy trial was planned. For the purpose 12 male Sprague Dawley rats were housed in the Animal Room of NIFSAT, University of Agriculture, Faisalabad. The environmental conditions were controlled throughout the trial like temperature $\left(23 \pm 2{ }^{\circ} \mathrm{C}\right)$ and relative humidity $(55 \pm 5 \%)$ along with $12 \mathrm{~h}$ light-dark period. During efficacy trials, four types of studies were conducted independently by involving normal and hyperglycemic rats. In study 1 , 2 and 3 rats were fed on high sucrose (60\% sucrose) diet and group 4 was given normal diet. Rats were given fig leaves tea and there plasma glucose level was monitored. Each study comprised of 3 rats. The details of this study are given in Table 1 .

Tea administration. The fig leaves tea infused in water was orally administered in a single dose per day for 15 days. The traditional Ficus carica leaf decoction was prepared by drying the leaves and preparing a decoction 
Table 1. Diet and treatment plan of normal and Hyperglycemic rats

\begin{tabular}{lllll}
\hline \hline Groups & Group I & Group II & Group III & $\begin{array}{l}\text { Group IV } \\
\text { Normal } \\
\text { rats }\end{array}$ \\
\cline { 2 - 4 } & & Diabetic rats & & Normal \\
\hline Diet & High & High & High & \\
& sucrose & sucrose & sucrose & \\
Treatments & No & Insulin+ Fig & Fig leaf & Fig leaf \\
& treatment & leaf tea & tea & tea \\
\hline \hline
\end{tabular}

( $50 \mathrm{~g} / \mathrm{kg}$ animal body weight); the decoction was then evaporated to the volume of $1 \mathrm{~mL} /$ animal.

Blood glucose determination. Blood samples were collected by puncture of tail by surgical blade at $0 \mathrm{~h}$ (before treatment) and $3 \mathrm{~h}$ and $24 \mathrm{~h}$ (after treatment). Glucometer (easygluco) was used to determine plasma blood glucose levels.

Statistical analysis. All values were expressed as mean \pm SD. The differences were compared using Analysis of Variance (ANOVA) (Steel et al., 1997). The significant differences among the treatment means were further analysed by Duncan Multiple Range Test (DMR).

\section{Results and Discussion}

Total phenol and flavonoid content of Ficus carica leaf extract. Water and methanol extract of leaves were prepared and were analysed for total phenol and flavonoid content (Fig. 1). Means presented in Table 2 shows that the total flavonoid content of water extract of Ficus carica leaves is $1.141 \%$ and that of methanol extract is $1.133 \%$ which are not significantly different. Means of total phenolic content of water and methanol extracts were $5.748 \mathrm{mg}$ and $4.29 \mathrm{mg}$, respectively, which shows that TPC of water extract was more as compared to TPC of methanol extract.

These results are collaborated with Konyaglioglu et al. (2005). It was concluded in their study that fig leaves have a high antioxidant activity. Water extract of fig leaves possessed highest total phenol and flavonoid content. But it is still unknown which antioxidants exhibit the greatest effect. Various researches have shown that flavonoids, quercetin and ferullic acid show hypoglycemic effects and are abundantly present in fig. leaves (El-Shobaki et al., 2010).

Sensory evaluation. Hedonic response is inevitable for the product acceptance and marketability. Good sensory
Table 2. Total phenol and flavonoid content of water and methanol extract of fig leaves

\begin{tabular}{llllll}
\hline \hline & \multicolumn{2}{c}{$\begin{array}{c}\text { Total flavonoid content } \\
\text { (\%) }\end{array}$} & & \multicolumn{2}{l}{$\begin{array}{l}\text { Total phenolic content } \\
\text { (mg/g dry mass) }\end{array}$} \\
\cline { 2 - 3 } Replicates & $\begin{array}{l}\text { Methanol } \\
\text { extract }\end{array}$ & $\begin{array}{l}\text { Water } \\
\text { extract }\end{array}$ & & $\begin{array}{l}\text { Methanol } \\
\text { extract }\end{array}$ & $\begin{array}{l}\text { Water } \\
\text { extract }\end{array}$ \\
\hline 1 & 1.091 & 1.142 & & 4.764 & 5.761 \\
2 & 1.135 & 1.127 & & 3.899 & 5.292 \\
3 & 1.173 & 1.153 & & 4.236 & 6.191 \\
Mean & 1.133 & 1.141 & & 4.29 & 5.748 \\
\hline \hline
\end{tabular}

response ensures consumer acceptance and confidence on the developed product. The functional and nutraceutical drinks were assessed for various sensory attributes including colour, taste, aroma, mixing ability, mouth feel and overall acceptability. Figure 2 shows the average response given by the panelists to each descriptive word which is marked on the corresponding axis, and the center of the graph represents the zero point of the scale used in the evaluation.

Biological effect of Ficus carica leaves tea on blood glucose, daily feed and water intake and body weight gain in diabetic and normal rats. The feed intake of all the groups showed different trends and fluctuations in feed intake as shown in Fig. 3. Group 1 (Diabetic) took normal feed intake $105.34 \pm 7.01 \mathrm{~g}$ /day and similar trend was observed in group 4 (Normal) $125.91 \pm 5.37 \mathrm{~g}$ /day. Minimum feed intake was observed in group 2 (Diabetic) $78.00 \pm 4.73$, in which insulin was supplemented

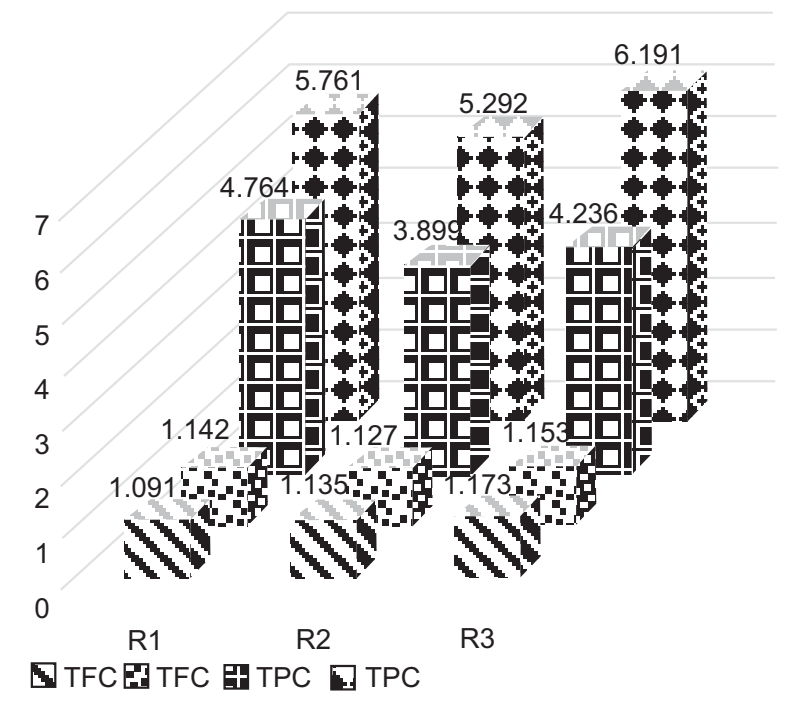

Fig. 1. Total phenolic content and total flavonoid content 


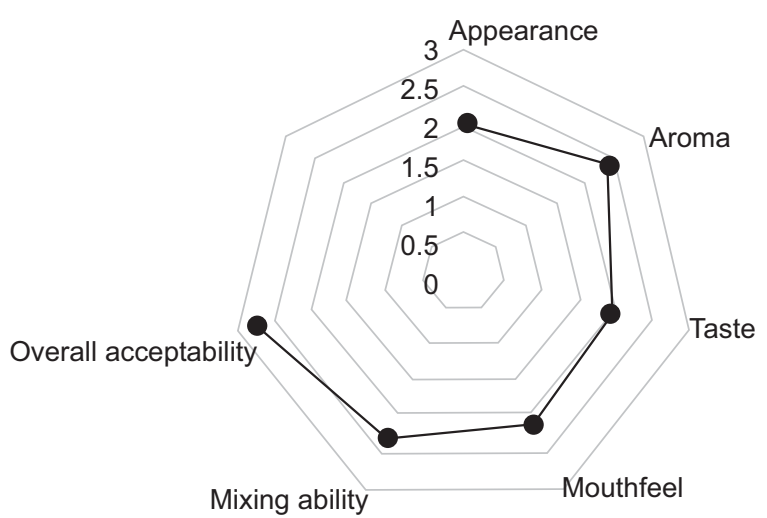

Fig. 2. Sensory evaluation.

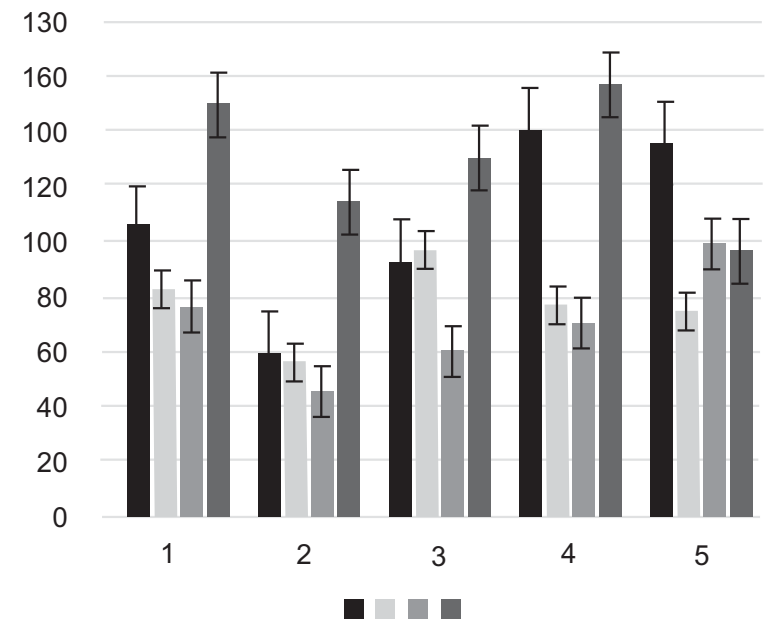

Fig. 3. Mean \pm SE of effect of study weeks on feed intake

with tea and group 3 (Diabetic) $74.34 \pm 5.85$ in which only tea was given.

Group 1 showed gradual decrease at first and then increase in feed intake. Group 2 showed low feed intake throughout the study. Group 3 showed fluctuation in trend and the feed intake whereas gradual increase was observed in group 4. So it can be concluded that Ficus carica leaves extract has no significant effect on feed intake in accordance with Perez et al. (2000).

Mean squares for drink intake showed non-momentous effects between groups whilst, time interval (weeks) imparted significant differences during the course of study (Fig. 4). Drink intake in the beginning in group $1,2,3$ and 4 was $138.75 \pm 21.64,142.50 \pm 33.26,117.50 \pm$ 29.55 and $143.75 \pm 20.14$, respectively. It was increased to $148.75 \pm 24.36,153.75 \pm 26.72$ and $158.75 \pm 24.86$ in group 1, 3 and 4 whereas decreased to $128.75 \pm 28.31$ in group 2. Therefore, it can be concluded that the administered extract of fig leaves was well tolerated by the rats as there was no significant reduction in drink intake before and after treatment like Perez et al. (2000) demonstrated.

Mean squares revealed that the bodyweight of rats in different groups varied significantly with study weeks. Body weight in Fig. 5 depicted that the diabetic group 1 which was not treated with tea gained maximum weight over weeks i.e. $163.67 \pm 16.59,203.33 \pm 14.71$, $223.00 \pm 12.01,250.00 \pm 12.22$ and $258.33 \pm 10.49$. All rats gained weight and the mean weight gain in groups

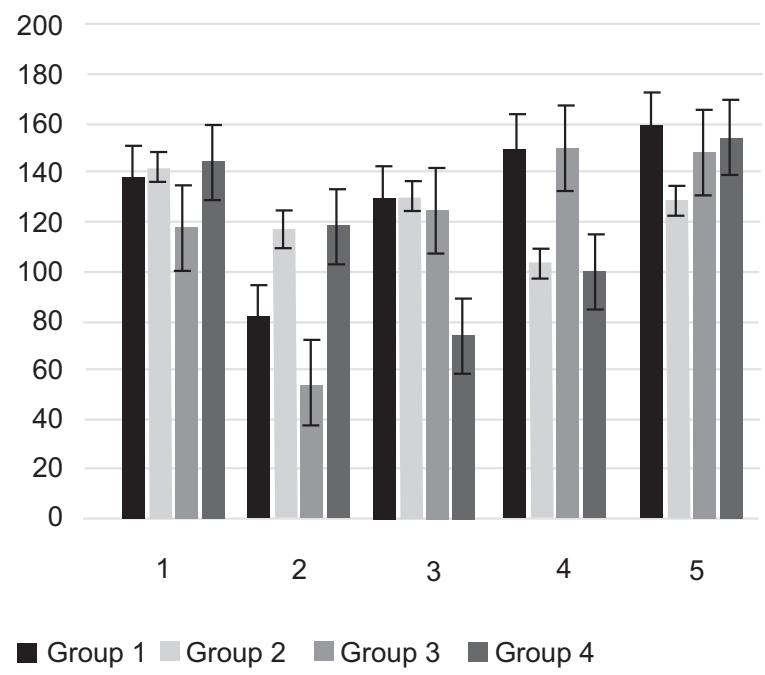

Fig. 4. Mean $\pm \mathrm{SE}$ of effect of study weeks on feed take water intake

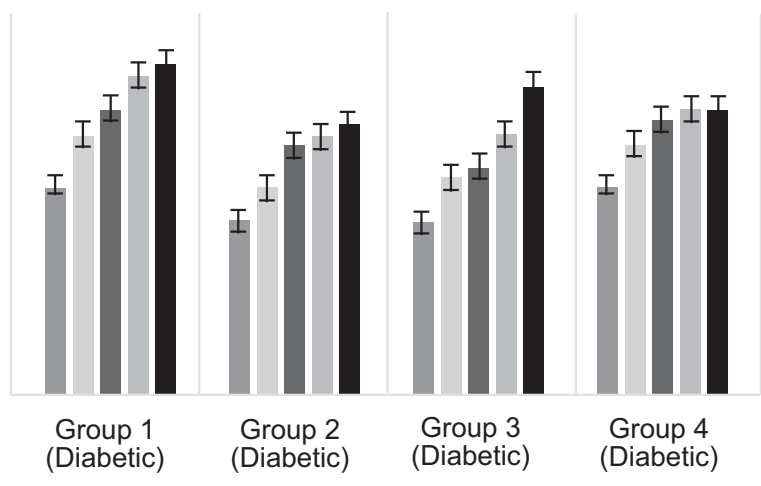

Day 0 Day 7 Day 14 Day 21 Day 28

Fig. 5. Mean \pm SE of effect of study weeks on weight 
$1,2,3$ and 4 was $219.67 \pm 10.43,181.13 \pm 9.94$, $185.67 \pm 10.34$ and $204.47 \pm 15.68$, respectively. These results are in line with El-Shobaki et al. (2010) who observed that groups treated with different levels of fig leaves have lower values of body weight gain as compared to non-treated groups. It may be due to the metabolic disturbances caused by them in one of the pathways or its side effects like inability to use carbohydrates including glycogenolysis, acidosis and lipolysis (Badr El-Din, 1997).

The data obtained from this study demonstrate that Ficus carica leaves tea exhibited a significant antidiabetic effect in diabetic rats (Fig. 6). Means of blood glucose of group 1, 2, 3 and 4 at $0 \mathrm{~h}$ are $140.29 \pm 1.91$, $147.31 \pm 2.37,131.05 \pm 1.58$ and $127.67 \pm 2.33$ and at $3 \mathrm{~h}$ are $139.52 \pm 1.89,56.21 \pm 3.38,113.36 \pm 1.71,110.74 \pm 1.48$ and at $24 \mathrm{~h}$ are $139.24 \pm 1.93,147.07 \pm 2.39,130.52 \pm 1.45$ and $127.86 \pm 2.35$. These results show that highest hypoglycemic effect of fig leaves tea was shown at $3 \mathrm{~h}$ which shows that leaves of Ficus carica show significant short term hypoglycemic effect and not so significant long term hypoglycemic effect. This finding confirm the results of Perez et al. (2000) which showed that aqueous and organic extracts of leaves of Ficus carica had similar effects in reducing hyperglycemia in diabetic rats.

Insulin administered in combination with Ficus carica leaves tea produced significant hypoglycemic effect (Fig. 7). However, when comparison was made between two insulin treatment groups (10U and $5 \mathrm{U}$ insulin) with $1 \mathrm{~mL}$ Ficus carica tea, no significant difference was observed with these two doses, which means that when given in combination of fig leaves tea even $50 \%$ decrease of dose of insulin didn't produce significant difference in blood glucose level. These results are also in

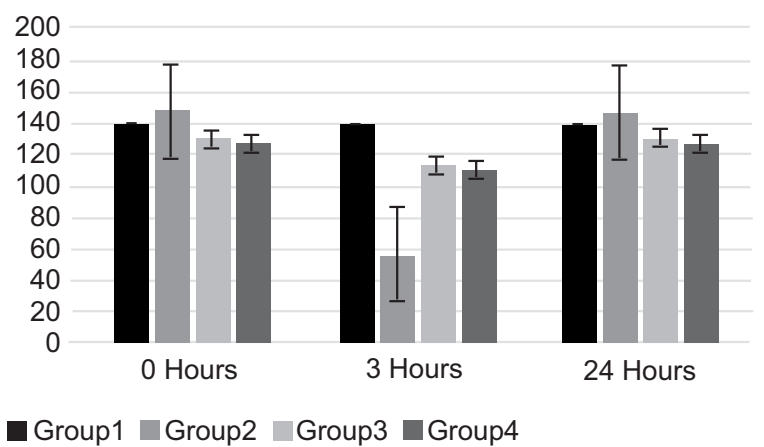

Fig. 6. Mean $\pm \mathrm{SE}$ of effect of Ficus carica leaves tea on blood glucose levels.

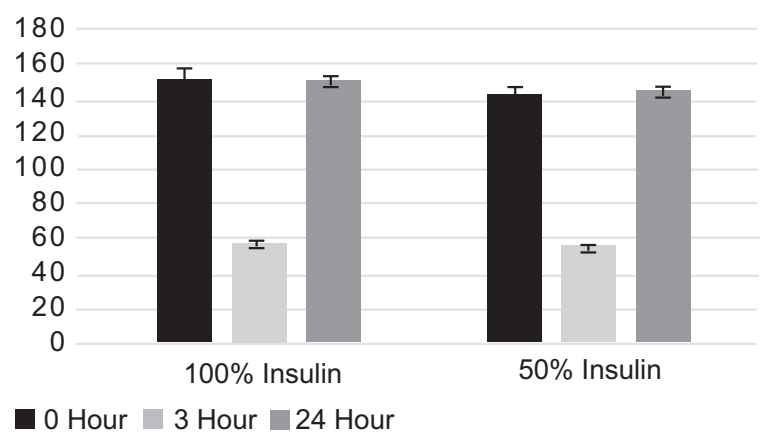

Fig. 7. Mean \pm SE of effect of Ficus carica leaves tea on insulin dose (10U and 5U).

agreement with the study of Serraclara et al. (1998) as they got $15.5 \%$ reduction in total daily insulin dose and no difference in blood glucose level was observed.

It can be concluded that the mechanism responsible for carrying hypoglycemic effect of Ficus carica leaves tea in diabetic rats could possibly be some insulin like effect through its additional effect when given in combination with insulin as it decreased the dose of insulin to almost $50 \%$ and/or increased the tissue sensitivity to insulin from the remaining unchanged $\beta$ cells. Therefore, fig leaves tea could be used as a supplement with insulin in order to increase the duration of action of insulin or its effect and/or reduces its doses and hence reduces its suspected side effects.

\section{Conclusion}

It can be concluded that leaves of Ficus carica show significant hypoglycemic effect and fig leaves tea can be used to exert a short term hypoglycemic effect in patients with diabetes. They also have an additional effect to insulin. It shows that bioactive moieties present in this drink are proved beneficial against hyperglycemia and have a potential to use in diet based therapy. More trials on humans should be conducted using fig leaves in various products

\section{References}

Badr El-Din, N. K. 1997. Effect of Panax ginseng extract on the nephrotoxicity of streptozotocin induced experimental diabetes. Egyptian Journal of Biochemistry, 15: 29-52.

Barolo, M.I., Mostacero, N.R., López, S.N. 2014. Ficus carica L.(Moraceae): An ancient source of food and health. Food Chemistry, 164: 119-127.

El-Shobaki, F.A., El-Bahay, A.M., Esmail, R.S.A., El- 
Megeid, A.A.A., Esmail, N.S. 2010. Effect of figs fruit (Ficus carica L.) and its leaves on hyperglycemia in alloxan diabetic rats. World Journal of Dairy \& Food Sciences, 5: 47-57.

Grover, J. K., Yadav, S., Vats, V. 2002. Medicinal plants of India with anti-diabetic potential. Journal of Ethnopharmacology, 81: 81-100.

Hayat, A. S., Shaikh, N. 2010. Barriers and myths to initiate insulin therapy for type 2 diabetes mellitus at primary health care centers of Hyderabad district. World Applied Sciences Journal, 8: 66-72.

Imran, A., Butt, M. S., Sharif, M. K., Sultan, J.I. 2013. Chemical profiling of black tea polyphenols. Pakistan Journal of Nutrition, 12: 261.

Jouad, H., Haloui, M., Rhiouani, H., El Hilaly, J., Eddouks, M. 2001. Ethnobotanical survey of medicinal plants used for the treatment of diabetes, cardiac and renal diseases in the North centre region of Morocco (Fez-Boulemane). Journal of Ethnopharmacology, 77: 175-182.

Kar, A., Choudhary, B.K., Bandyopadhyay, N.G. 2003. Comparative evaluation of hypoglycaemic activity of some Indian medicinal plants in alloxan diabetic rats. Journal of Ethnopharmacology, 84: 105-108.

Keneth, J. 2000. Medical uses of Ficus carica. Plants and Medicine, 122: 43.

Konyalıglu, S., Saglam, H., Kıvçak, B. 2005. $\alpha$-tocopherol, flavonoid, and phenol potential of Ficus carica leaves. Pharmaceutical Biology, 43: 683-686.

Leporatti, M.L., Ivancheva, S. 2003. Preliminary comparative analysis of medicinal plants used in the traditional medicine of Bulgaria and Italy. Journal of Ethnopharmacology, 87: 123-142.

Meilgaard, M., Civille, G.V., Carr, B.T. 2007. Overall difference tests: does a sensory difference exist between samples. Sensory Evaluation Techniques, 4: 63-104.

Merzouki, A., Ed-Derfoufi, F., Mesa, J.M. 2000. Contribution to the knowledge of Rifian traditional medicine II. Folk medicine in Ksar Lakbir district (NW Morocco). Fitoterapia, 71: 278-307.

Murray, MT., Pizzorno, J.E. 1999. Botanical medicinea modern perspective. In: Textbook of Natural Medicine, pp. 123-124, $14^{\text {th }}$ edition, Edinburgh, Churchill Livingstone, UK.

Musabayane, C.T., Gondwe, M., Kamadyaapa, D.R., Chuturgoon, A.A., Ojewole, J.A.O. 2007. Effects of Ficus thonningii (Blume)[Morarceae] stem-bark ethanolic extract on blood glucose, cardiovascular and kidney functions of rats, and on kidney cell lines of the proximal (LLC-PK1) and distal tubules (MDBK). Renal Failure, 29: 389-397.

Patil, V.V., Patil, V.R. 2011. Evaluation of antiinflammatory activity of Ficus carica Linn. leaves. Indian Journal of Natural Product and Resources, 2: 151-155.

Perez, C., Canal, J.R., Torres, M.D. 2003. Experimental diabetes treated with Ficus carica extract: effect on oxidative stress parameters. Acta Diabetologica, 40: $3-8$.

Perez, C., Canal, J.R., Campillo, J. E., Romero, A., Torres, M.D. 1999. Hypotriglyceridemic activity of Ficus carica leaves in experimental hypertriglyceridaemic rats. Phytotherapy Research, 13: 188-191.

Rashidi, A.A., Noureddini, M. 2011. Hypoglycemic effect of the aromatic water of leaves of Ficus carica in normal and streptozotocin induced diabetic rats. Pharmacology Online, 1: 372-379.

Serraclara, A., Hawkins, F., Perez, C., Dominguez, E., Campillo, J.E., Torres, M.D. 1998. Hypoglycemic action of an oral fig-leaf decoction in type-I diabetic patients. Diabetes Research and Clinical Practice, 39:19-22.

Singh, R. K., Mehta, S., Jaiswal, D., Rai,P.K., Watal, G. 2009. Antidiabetic effect of Ficus bengalensis aerial roots in experimental animals. Journal of Ethnopharmacology, 123: 110-114.

Singleton, V. L., Rossi, J. A. 1965. Colorimetry of total phenolics with phosphomolybdic-phosphotungstic acid reagents. American Journal of Enology and Viticulture, 16: 144-158.

Sirisha, N., Sreenivasulu, M., Sangeeta K., Chetty, C.M. 2010. Antioxidant properties of Ficus species-A Review. International Journal of Pharmtech Research, 2: 2174-2182.

Steel, R.G.D., Torrie, J.H., Dickey, D. 1997. Principles and Procedures of Statistics: A biometrical Approach, $3^{\text {rd }}$ edition., McGraw Hill Book Co., Inc., New York, USA.

Wadood, N., Wadood, A., Nisar, M. 2003. Effect of Ficus relegiosa on blood glucose and total lipid levels of normal and alloxan diabetic rabbits. Journal of Ayub Medical College (JAMC), 15: 40-42.

Zohary, D., Hopf, M., Weiss, E. 2012. Fruit Trees and Nuts. In: Domestication of Plants in the Old World. 122 pp.Oxford University Press, UK. 